\title{
Postmenopausal hormone use was associated with decreased total mortality
}

\author{
Grodstein F, Stampfer MJ, Colditz GA, et al. Postmenopausal hormone therapy and mortality. N Engl J Med 1997 Jun \\ 19;336:1769-75.
}

\section{Objective}

To determine whether use of hormone replacement therapy (HRT) was associated with total mortality.

\section{Design}

A nested case control study of participants in the Nurses' Health Study.

\section{Setting}

Community based study in the USA.

\section{Participants}

121700 nurses (all women), who were aged $30-55$ years at baseline, completed questionnaires in 1976 and every 2 years until 1994. Women were included in this analysis if they reported being postmenopausal. Exclusion criteria were reported cardiovascular disease or cancer before menopause. 3637 women died during follow up and were considered to be the case patients. All but 50 women who died were matched with 10 control women who were alive either at the date of the case patient's death or diagnosis of the fatal illness $(n=34625)$.

\section{Assessment of risk factors}

HRT use was taken from questionnaires and was classified into current use, past use, and never used. Questionnaires also provided data on risk factors used for adjustment in the analysis: cardiovascular risk, diabetes, hypertension, high cholesterol concentrations, past oral contraceptive use, parity, family history of myocardial infarction, breast cancer in mother or sister, age, age at menarche and menopause, type of menopause, smoking status, body mass index, and time period of case patient's death.

\section{Main outcome measures}

All cause mortality and mortality from coronary heart disease, stroke, all cancers, and breast cancer.

\section{Main results}

Compared with "never use" of HRT, current use was associated with a lower adjusted risk for all cause mortality (relative risk [RR], $0.63,95 \%$ CI 0.56 to 0.70 ), coronary heart disease mortality (RR 0.47 , CI 0.32 to 0.69 ), and all cancer mortality (RR 0.71 , CI 0.62 to 0.81 ) but not with mortality from stroke (RR 0.68 CI 0.39 to 1.16 ) or breast cancer (RR 0.76 , CI 0.56 to 1.02 ). Past use of HRT was not associated with decreased risk for any outcome. The survival benefit for all cause mortality decreased with the length of time HRT was taken (RR for $<5$ years 0.56 , CI 0.48 to 0.65 ; RR for 5 to 9 years 0.60 , CI 0.50 to 0.72 ; and RR for $\geqslant 10$ years 0.80 , CI 0.67 to 0.96 ). Subgroup analysis showed that women who were at high risk for cardiovascular disease had a greater benefit in all cause mortality (RR 0.51 , CI 0.45 to 0.57 $v$ RR for low risk women 0.89 , CI 0.62 to 1.28 ).

\section{Conclusions}

Current use of HRT reduced all cause mortality in women. The survival benefit decreased with increasing duration of use. Women with high cardiovascular risk showed the highest benefit from use of HRT.

Source of funding: National Institutes of Health.

For article reprint: $\mathrm{Dr} F$ Grodstein, Channing Laboratory, 181 Longwood Avenue, Boston, MA 02115, USA. Fax +1 6175252008 .

\section{Commentary}

Four important messages come from the Nurses' Health Study. All cause mortality was lower among women who used HRT compared with those who had never used HRT. The largest reduction was for mortality from coronary heart disease and all cause mortality among women with cardiovascular risk factors. Survival benefit decreased with longer duration of HRT use. A large, but not statistically significant trend was seen in the increase in death from breast cancer.

Was this study done well enough to produce believable results? The study included prospective data collection (with nested case control analysis), a large sample size, determination of HRT use before death or diagnosis of the fatal disease, update of HRT use through biennial questionnaires, careful matching, 98\% follow up for deaths, and careful determination of cause of death. One potential weakness was the reliance on self reported HRT use.

Are the findings consistent with previous research? Other studies have also shown lower risks of fatal and non-fatal coronary heart disease among postmenopausal women taking oestrogen. ${ }^{12}$ With respect to breast cancer, however, inconsistent associations have been seen with long term HRT use. $^{3-5}$ The recently launched Women's Health Initiative, a multicentre randomised trial with 25000 women assigned to placebo, oestrogen alone, or combined oestrogen progestin therapy, should provide important new evidence on the effects of HRT. ${ }^{6}$

What do we do in the meantime? Women with at least one major cardiovascular risk are likely to benefit from HRT, but the risks may outweigh the benefits among women with increased risk of breast cancer. Counselling should include the woman's full participation, with deci- sions based on individual patient risk factors for disease, clear understanding of the probable benefits and risks of HRT, and personal preferences.

Dorothy-Anne Mills, RN, MHSc Nurse Practitioner, Family Practice Unit Hamilton Health Sciences Corporation Hamilton, Ontario, Canada

Linda Jones, RN, BScN

Nurse Practitioner, South-East Ottawa Centre for a Healthy Community Ottawa, Ontario, Canada

1 Grady D, Rubin SM, Petitti DB et al. Ann Intern Med 1992;117:1016-37.

2 Barrett-Conner E, Bush TL. JAMA 1991;265: 186-7.

3 Steinburg KK, Thacker SB, Smith J, et al.JAMA 1991;265:1985-90

4 Sillero-Arenas M, Delgado-Rodriguez M, Sillero-Arenas M, Delgado-Rodriguez M,
Rodrigues-Cateras R, et al. Obstet Gynecol 1992; $99: 286-94$.

5 Colditz GA, Egan KM, Stampfer MJ. Obstet

Gynecol 1993;168:1473-80.
6 Rossouw JE, Finnegan LP, Harlan WR, et al.J Am Med Wom Assoc 1995;50:50-5. 